\title{
Crafting theoretical value in management research article discussion sections
}

\author{
Fei-Wen Cheng \\ National Chiayi University (Taiwan) \\ chengfw@gmail.com
}

\section{Abstract}

The enactment of theoretical contribution in research articles (RAs) is a critical academic writing practice for showcasing the scientific progress of a disciplinary field. To decide how novel research strengthens a discipline's current state of knowledge necessitates evaluating the new empirical results based upon its specific academic norms. Yet the academic values utilized to formulate theoretical advancement have been little studied in the literature. Drawing upon pertinent evaluation frameworks, the purpose of this study is to uncover how RA authors negotiate the theoretical value of novel research by conducting a rhetorical analysis of 60 research article discussion sections taken from four prestigious management journals. The present investigation reveals a tentative taxonomy of six rhetorical appeal types deployed by RA authors to articulate the value of novel research in the knowledge market. The widespread use of these appeals in management research article discussion sections indicates that a strong promotional orientation is prevalent in the rhetoric of the journals examined. The findings of this research have theoretical and pedagogical implications for academic evaluation and promotion, as well as for teaching academic writing.

Keywords: academic value, theoretical contribution, academic evaluation, discussion section, academic discourse.

\section{Resumen}

La construcción del valor teórico en las secciones de discusión de artículos de investigación en el área de las ciencias de la administración

Mostrar cuál es la contribución teórica de un artículo de investigación es una práctica de escritura académica fundamental para poner de manifiesto el progreso científico que se produce en una determinada disciplina. Para decidir 
en qué medida la nueva investigación refuerza el estado actual de conocimiento en una disciplina es necesario evaluar los nuevos resultados empíricos obtenidos con base en sus normas académicas específicas. No obstante, los valores académicos utilizados para formular los avances teóricos apenas han sido estudiados en la bibliografía. A partir de diferentes marcos de evaluación pertinentes, el objetivo de este estudio es desvelar cómo los autores de artículos de investigación negocian el valor teórico de la nueva investigación a través de un análisis retórico de las secciones de discusión de 60 artículos de investigación procedentes de cuatro revistas prestigiosas en el ámbito de las ciencias de la administración. El presente trabajo ofrece una taxonomía provisional de seis tipos de apelaciones retóricas utilizadas por los autores de artículos de investigación para articular el valor de novedad en el mercado del conocimiento. El extendido uso de estas apelaciones en las secciones de discusión de los artículos de investigación de ciencias de la administración evidencia que prevalece una fuerte orientación promocional en la retórica de las revistas examinadas. Los hallazgos de este trabajo tienen implicaciones teóricas y pedagógicas para la evaluación y promoción académicas, así como para la enseñanza de la escritura académica.

Palabras clave: valor académico; contribución teórica; evaluación académica; sección de discusión; discurso académico.

\section{Introduction}

Demonstrating the contribution of new research to the target disciplinary field is essential when seeking academic publication (Locke \& GoldenBiddle, 1997; Martín \& León Pérez, 2014; Mur-Duenãs, 2014; Hyland, 2015). Prior research has indicated that the contribution is likely to be manifested in the introduction (Swales, 2004; Martín \& León Pérez, 2014; Mur-Duenãs, 2014) and discussion (Nwogu, 1997; Yang \& Allison, 2003; Basturkmen, 2012; Tessuto, 2015) sections of a research article (RA) via a move/step which states the value or significance of the research. Though insightful, these studies rarely go beyond statements of the general contributions of the research in order to distinguish the specifics of its theoretical significance from its methodological, pedagogical, or other types of contributions. Thus, a well-defined template for assessing a study's theoretical contribution is unavailable.

The notion of theoretical contribution is regarded as replete with "ambiguity and intricacy" (Corley \& Schinoff, 2017, p. 11). For clarity, and given that intellectual progress within a specific discipline is documented in academic 
publications, "theory" in this study is broadly conceived as the scientific knowledge legitimized by an academic discipline and published in the existing body of literature. In this sense, theoretical contribution is signified by the discursive choices describing a new study's contribution to advance the disciplinary knowledge base (Bartunek \& Rynes, 2010; Corley \& Gioia, 2011; Corely \& Schinoff, 2017). The construction of theoretical contribution thus requires tacit knowledge of disciplinary academic norms to decide how new research adds to the corpus of disciplinary knowledge in the published literature. It entails complex rhetorical maneuvering to evaluate the empirical results based upon a communal value system (Thompson \& Hunston, 2000; Giannoni, 2010) in a specific scientific field. However, scant attention has been paid to the types of evaluation norms underlying these discursive practices, hereafter dubbed "theoretical value".

The present study was motivated by both theoretical and pedagogical interests. First, as noted above, little research attention has been paid to the discursive construction of theoretical value, which holds true for the area of English for Specific Purposes/ English for Academic Purposes (ESP/EAP) scholarship. Second, several studies have indicated that writing such discussions is a formidable task for apprentice writers (Peacock, 2002; Basturkmen, 2009; Swales \& Feak, 2012; Le \& Harrington, 2015). By integrating typologies of academic values proposed in the established literature with the theoretical frameworks of move/step schemes, this study was undertaken to probe into the evaluative parameters for crafting the description of theoretical contribution in RA discussion sections. Discussion sections warrant further scrutiny because, as Lewin, Fine and Yang (2001) put it, they are "inviting applause" for the new study (p. 62) by evaluating and justifying the value of its empirical results theoretically, methodologically and/or practically for promotional purposes. It is hoped that the present study can shed more light on this critical act and thus serve the pedagogical purpose of clarifying how to evaluate the new findings so as to warrant claims of their theoretical contribution in the RA discussion section. As academics face intense competition internationally for publishing in renowned journals, understanding how to formulate an effective account of the theoretical contribution of their empirical results is crucial in today's academic world. 


\section{Academic values in the RA genre}

In the present study, academic values are conceived as norms underpinning the social and cultural dimension of academic evaluation across disciplines (Giannoni, 2010). Many approaches to evaluation language have been advocated in the past few decades, for instance, Biber and Finegan's (1988) stance, Hunston and Thompson's (2000) evaluation, Hyland's (2005) metadiscourse, Martin and White's (2005) appraisal, and Bednarek's (2006) parameter-based framework of evaluation. These frameworks have some common strands but give prominence to different facets of evaluation phenomena (see excellent reviews in Bednarek, 2006, and Hunston, 2011). Although these approaches to evaluation language are fairly comprehensive and account for a diverse variety of the related linguistic resources, the purpose of this study is to examine the academic criteria used to evaluate and promote the theoretical value of empirical findings. Frameworks documenting specific value evaluation parameters associated with academic discourse are appropriate to meet this goal. While academic values are formulated within particular disciplines (Giannoni, 2010), genres (Swales \& Burke, 2003) and language-specific cultures (Martín \& León Pérez, 2014), the focus of the present study centers on these associated with the RA genre across disciplines. Table 1 shows several taxonomies of academic values on RA genre, though divergent in scope as well as evaluation entities.

\begin{tabular}{|c|c|c|c|c|c|}
\hline Research & $\begin{array}{c}\text { Hunston } \\
\text { (1993) }\end{array}$ & $\begin{array}{l}\text { Thetela } \\
\text { (1997) }\end{array}$ & $\begin{array}{c}\text { Swales \& } \\
\text { Burke } \\
(2003)\end{array}$ & $\begin{array}{c}\text { Giannoni } \\
(2010)\end{array}$ & $\begin{array}{c}\text { Corley \& } \\
\text { Gioia }(2011)\end{array}$ \\
\hline $\begin{array}{l}\text { Evaluation } \\
\text { entities }\end{array}$ & Results & Findings & Not specified & Wide variety & $\begin{array}{l}\text { Theoretical } \\
\text { contribution }\end{array}$ \\
\hline $\begin{array}{l}\text { Academic } \\
\text { values }\end{array}$ & $\begin{array}{l}\text { Reasonableness } \\
\text { Consistency } \\
\text { Supportiveness } \\
\text { Usefulness } \\
\text { Importance } \\
\text { Reliability }\end{array}$ & $\begin{array}{l}\text { Significance } \\
\text { Certainty }\end{array}$ & $\begin{array}{l}\text { Deviance } \\
\text { Relevance } \\
\text { Assessment } \\
\text { Acuity } \\
\text { Aesthetic } \\
\text { appeal } \\
\text { Size } \\
\text { Strength }\end{array}$ & $\begin{array}{l}\text { Goodness } \\
\text { Size } \\
\text { Novelty } \\
\text { Relevance } \\
\text { Value } \\
\text { Timing } \\
\text { Impact } \\
\text { Complexity } \\
\text { Generality } \\
\text { Completeness } \\
\text { Centrality } \\
\text { Appeal }\end{array}$ & $\begin{array}{l}\text { Originality } \\
\text { Utility }\end{array}$ \\
\hline
\end{tabular}

Table 1. Comparison of academic value frameworks.

As illustrated, a wide spectrum of proposed academic values accounts for the variation of evaluation approaches while shedding some light on the 
value system underlying academic discourse across disciplines. One line of scholarship has suggested an all-inclusive framework of value categories prototypical in the RA genre, demonstrating the interface between value parameters and their linguistic manifestations. By focusing exclusively on the use of adjectives as evaluative markers, Swales and Burke (2003) found that seven categories of adjectives predominated across the Michigan Corpus of Academic Spoken English (MICASE), and Hyland's RA written corpus, such as "deviance", exhibiting the extent to which entities are related to each other (e.g., "“strange," "typical"); "assessment", denoting a general evaluation of any entities (e.g., "exciting," "horrible," "uninteresting'); and "acuity", relating to assessment of the intellectual quality of the work (e.g., "intelligent," "stupid"). Their results showed that three values, "size", "relevance", and "assessment", occur predominantly across both spoken and written academic genres, and that "relevance" is the most prevalent of the three in Hyland's written corpus, where it is also more prevalent than in the MICASE. Giannoni (2010) also proposed a comprehensive framework of value parameters in RAs based on an analysis of 10 disciplines selected from the natural sciences, applied sciences, human sciences, social sciences and mathematical sciences. To account for disciplinary differences, more categories were added to those in previous studies ("size", "relevance", and "impact"), including "novelty", "appeal" (e.g., interesting), "complexity", "generality" (e.g., general/specific), "completeness", and "centrality". The four most prevalent values across disciplines in decreasing order are "relevance", "size", "goodness" and "novelty", though "relevance" and "goodness" are less prominent in the hard sciences than in the humanities/social sciences.

Another line of scholarship focuses on how value parameters vary depending on their evaluated entities, further illuminating the relationships between evaluated entities and value parameters in RA genres across disciplines. In a pioneering study, Hunston (1993) identified different entities in experimental research articles, such as the research event, hypotheses/interpretation, and findings, and their corresponding evaluation criteria. The values assigned to research results as a focal entity are shown in Table 1; "reasonableness", "consistency" and "supportiveness" refer to the fit between relationship of findings and expectations, other research, and theory. "Usefulness" indicates the capacity of the research to evaluate existing theory, while "reliability" and "importance" are self-evident criteria. Hunston's framework was further modified in Thetela's (1997) study. By 
analyzing all grammatical forms of attitudinal language in 60 RAs in the areas of history, economics, psychology and applied linguistics, Thetela reported that across disciplines, "significance" and "certainty" were the values most often utilized to evaluate results, whereas "usefulness" and "control" were most often associated with research methods. Of particular relevance to the present research, Corley and Gioia (2011) identified "originality" and "utility" as two attributes constituting the basis for claiming and assessing theoretical contributions in management literature. However, these two general value parameters are too broad in scope to distinguish textual evidence specific to how any theoretical contribution is realized.

The above frameworks reveal features of a broad range of academic values in the RA genre across various disciplines, despite differences in the use of terminology and conceptual frameworks and in the research purpose across studies. Though possibly useful as research coding tools or as a vocabulary for presenting epistemic knowledge, these frameworks lack the specificity to make clear connections to RA rhetorical structures and therefore pedagogical value. That is, they index general values that can be deployed and featured in discussion, but not under what occasions it is appropriate to exploit them or how to do so in a strategic and sophisticated manner. Although the value parameters for research results listed in the studies by Hunston (1993), Thetela (1997) and Corley and Gioia (2011), are closely related to the present research, they need to be substantiated in specific rhetorical acts to show how a theoretical value to the target discipline is negotiated in new research.

The importance of when to apply which value may be observed in recent micro-analyses of evaluative parameters of specific moves/steps in RA introductions across disciplines. Kwan, Chan and Lam (2012) examined the use of evaluation criteria in one specific step, "counter-claiming" in "Move 2: Establishing a niche" in the field of information systems. They found that in critiques of prior literature in this discipline, RA value parameters center on "validity", "methodological flaws" and "explanatory power" for evaluation entities such as theories, research design or practice, whereas the parameters focus on "cost", "accuracy", "capacity", "reliability" and "scalability" for non-epistemic entities, such as design and performance of IT artefacts. Likewise, in a study of three business-related disciplines, finance, management and marketing, Lindeberg (2004) reported six categories of evaluation criteria utilized in the "claims of centrality" Step of introduction Move 1: "authority" (i.e., a named authority from a disciplinary 
field or society), "economy" (i.e., the magnitude of the researched phenomenon in financial terms), "practitioner" (i.e., the usefulness of the topic), "research" (i.e., the importance of the topic), "scope" (i.e., the prevalence of the topic in business or society in general), and "topicality" (recency or novelty of the topic). These evaluation criteria, glossed as "rhetorical appeals", are adapted to the same rhetorical step in Wang and Yang's (2015) study of applied linguistics RAs. In line with Lindeberg (2004), four similar criteria were prevalent in assessing the research domain under investigation: "salience" (importance), "magnitude" (prevalence), "topicality" (newness/recency), and "problematicity" (conflicts/difficulties).

Though none of these studies centers on RA discussion sections, they do enhance our understanding of the academic values underpinning a specific rhetorical step, and their findings pinpoint the importance of connecting academic value with rhetorical schemes. Such connections may enable EAP practitioners to design awareness-raising pedagogical activities, and provide effective rhetorical tools that novice researchers can apply when composing RAs. Following this stream of research, the present study set out to elucidate the craft of framing theoretical value by examining the types of academic norms that are utilized in management RA discussion sections to anchor a work's theoretical contribution. The academic values mobilized to articulate and promote a study's theoretical contribution are termed "appeals" in this research, reflecting previous uses in the literature. The term "rhetorical appeal" utilized in Lindeberg's (2004) and Wang and Yang's (2015) studies reflects the positive value associated with a specific evaluative parameter, borrowing Swales' conceptualization of appeal-making as a promotional strategy (Lindeberg, 2004; Wang \& Yang, 2015). Its positive and promotional features distinguish it from 1) value parameters, which extend through a positive to negative continuum and form the basis for appeal-making; and 2) the traditional move/step, which does not instantiate these two features simultaneously.

\section{Method}

\subsection{Data collection}

\subsubsection{The field of management}

The importance of constructing theoretical contributions in academic publication is overtly emphasized in the discipline of management science, 
to which a virtual obsession with theories has been ascribed (Hambrick, 2007; Corley \& Gioia, 2011; Cornelissen \& Durand, 2014; Shaw, Bansal, \& Gruber, 2017) as “an outgrowth of the field's efforts to demonstrate academic worthiness" (Hambrick, 2007, p. 1347). Given that management science is a much younger discipline than other social sciences (i.e., economics, sociology, and psychology), it has self-identified as a one-sided borrower of theories from them (Colquit \& Zapata-Phelan, 2007; Rousseau, 2007; Corley \& Gioia, 2011; Cornelissen \& Durand, 2014), and in order to establish itself as a valid academic field with scientific rigor, major efforts have been dedicated to theory building. This priority can be observed in the wealth of theoretical and empirical studies addressing the definition of theory in management and organization fields (Whetten, 1989; Sutton \& Staw, 1995; Weick, 1995), the taxonomies or criteria used to assess theoretical contributions (Colquit \& Zapata-Phelan, 2007; Corley \& Gioia, 2011), and the thinking tools used to facilitate theoretical innovation such as "disciplined imagination", "problematization" and "thickening of abstraction", as noted in Cornelissen and Durand's (2014) comprehensive review. This critical demand for new and discipline-specific theories reflects the requirements of academic publication for explicit articulation and justification of theoretical contributions, that is, the extent to which the study moves the field beyond its current status and transforms it, so that the discipline can maintain and build its legitimacy and relationships within the larger academic community (Corley \& Gioia, 2011). This interdisciplinary focus and its concomitant disciplinary emphasis on developing theoretical maturity through academic publication renders management an interesting field in which to observe the rhetorical practice of crafting theoretical contribution and to delineate the discursive mechanisms behind its formation.

\subsubsection{Corpus compilation}

A total of 60 RA discussion sections were collected from four internationally prestigious management journals, based upon high impact factors documented by the ISI Web of Science (2013) and consultations with disciplinary experts: the Academy of Management Journal (AMJ), the Journal of Management (JOM), Administrative Science Quarterly (ASQ), and the Journal of Management Studies (JMS). Empirical articles published in 2011 or 2012 with a distinct Introduction-Method-Result-Discussion (IMRD) format were purposefully chosen from each journal and were then shortlisted. Fifteen 
articles were then randomly selected to constitute the corpus, drawing from the odd numbers on the shortlist articles of each journal. Table 2 summarizes basic information on the resulting corpus.

\begin{tabular}{lccc|}
\hline Journals & Articles & $\begin{array}{c}\text { Overall length of all } \\
\text { discussions }\end{array}$ & $\begin{array}{c}\text { Mean length (SD) of } \\
\text { all discussions }\end{array}$ \\
\hline Academy of Management Journal & 15 & 41,939 & $2,796(400.9)$ \\
Administrative Science Quarterly & 15 & 33,150 & $2,210(569.3)$ \\
Journal of Management & 15 & 37,498 & $2,499.9(625.2)$ \\
Journal of Management Studies & 15 & 31,077 & $2,071.8(466.6)$ \\
Total & 60 & 143,664 & $2,394.4(581.7)$
\end{tabular}

Table 2. Basic corpus information.

\subsection{Data recording}

Prior to identifying the types of academic values or rhetorical appeals manifested in formulations of theoretical contribution, it was necessary to categorize the move/step associated with this rhetorical act. For this purpose, the data coding process started with developing a preliminary analysis of the whole schematic structure of management RA discussions and proceeded through the steps of conducting an inter-coder reliability test of this structure, identifying instances of the rhetorical act of highlighting theoretical contributions, and finally analyzing and classifying the academic values underlying this act.

To develop an initial move scheme, the well-known Yang and Allison (2003) model was revised in combination with additional rhetorical choices reported in Lewin, Fine and Young (2001) and Kanoksilapatham (2005), to capture more comprehensively the rhetorical functions found in management discussions. To fine-tune this initial classification of move/step elements in pursuit of a comprehensive account of possible structures, the researcher went through a multi-iteration procedure until all the possible move/step elements were exhausted. Based on the initial coding of half of the target corpus, a tentative rhetorical scheme comprising six moves with embedded steps was developed, in which most rhetorical schemes identified in the previous literature were represented with some newly added elements frequently manifested in the target corpus. Among the six moves, Move 2, "Claim research value", which serves as the starting point for the present study, includes the following three embedded steps: Step 1, "Stating theoretical implication"; Step 2, "Showcasing the theoretical background"; 
and Step 3, "Justifying the theoretical value". Each of these three steps in Move 2 also consists of several sub-steps.

This tentative scheme was subject to further inter-coder reliability analysis with three inter-coders, including two management academics and one native English-speaking faculty member working within a foreign language department. All had been educated in English-speaking countries and published widely in high-impact international journals. For the sample of 15 discussion sections (25\%) randomly selected from the target corpus of 60 , the obtained Cohen's kappa values ranged from .90 to .93 among the researcher and three coders across the six moves, while it was from .75 to .81 for the three steps of Move 2. Most of the coding discrepancies centered on the boundaries between steps, particularly among the researcher and the two management academics, but all of these were resolved through constructive debates.

The remaining 45 discussion sections were then analyzed by the researcher, starting by demarcating the different moves across the corpus, followed by the three constituent steps of Move 2 and their embedded substeps, focusing primarily on prominent semantic/linguistic features. In this move, the substep of Step 1, dubbed as Step 1A, "Highlighting theoretical contribution to the field", points to the deployment of explicit lexicogrammatical resources to signal the theoretical contribution. It serves as the basis for identifying the rhetorical appeals underlying each theoretical contribution and was found in 56 of the 60 articles (93\%) (it was absent from both JOM's and JMS's two articles). It also had the highest frequency of occurrence $(\mathrm{N}=314,92 \%)$ in the corpus. The heavy presence of this substep indicates the emerging trend that management scholars place a high premium on advertising their original contribution in response to the strong competition to publish in high-profile international journals.

The subsequent analysis focuses on the rhetorical appeals utilized in the highly promotional step 1A, "Highlighting theoretical contribution to the field". Following the procedures documented in Giannoni (2010), the categories of rhetorical appeals were first sorted by applying lexical and semantic criteria to group the pertinent linguistic elements together into conceptually similar categories. An appeal label was then assigned to each whole unit of this rhetorical sub-step, with reference to the taxonomy of academic values or appeals specified in the literature noted above. Overall, six rhetorical appeals were categorized as explicated in the results section. Once the benchmarking of rhetorical appeals had been completed, the 
ensuing analysis was undertaken manually to calculate the occurrence rate of each appeal.

\section{Results}

A total of 319 instances of appeals were coded among the 56 RA discussion sections, omitting the four that did not include this substep, averaging 5.70 instances per discussion. With the scope of the analysis restricted to lexicogrammatical features, six categories of appeals utilized to construct theoretical contribution were identified, namely, appeals to scope, value, novelty, gap-filling, importance, and usefulness. Each appeal with its linguistic manifestations, indicated by boldfaced markings, is discussed in the following subsections. Table 3 presents the raw counts and percentages of the occurrence of these types of appeal in the corpus and the number of articles containing each appeal.

\begin{tabular}{|c|c|c|c|c|c|c|c|c|}
\hline Research & $\begin{array}{c}\text { Scop } \\
\text { e }\end{array}$ & $\begin{array}{c}\text { Novelt } \\
y\end{array}$ & $\begin{array}{c}\text { Valu } \\
\text { e }\end{array}$ & $\begin{array}{c}\text { Gap } \\
\text { fillin } \\
\mathbf{g}\end{array}$ & $\begin{array}{c}\text { Importanc } \\
\text { e }\end{array}$ & $\begin{array}{c}\text { Usefulnes } \\
\mathbf{s}\end{array}$ & $\underset{*}{\text { N.C. }}$ & Total \\
\hline Instances & 135 & 55 & 54 & 38 & 29 & 7 & 1 & $\begin{array}{c}\mathrm{N}=31 \\
9\end{array}$ \\
\hline $\begin{array}{l}\text { Percentage } \\
\mathrm{s}\end{array}$ & $\begin{array}{c}42 \% \\
46 \\
(77 \%)\end{array}$ & $\begin{array}{c}17 \% \\
31 \\
(52 \%)\end{array}$ & $\begin{array}{c}17 \% \\
33 \\
(52 \%)\end{array}$ & $\begin{array}{c}12 \% \\
25 \\
(42 \%)\end{array}$ & $\begin{array}{c}9 \% \\
19 \\
(32 \%)\end{array}$ & $\begin{array}{c}2 \% \\
7 \\
(12 \%)\end{array}$ & & $\mathrm{N}=60$ \\
\hline
\end{tabular}

Table 3. Distribution of different types of appeals.

* Note. N.C. = instance cannot be assigned to any appeal category.

The predominant category is the appeal to scope, followed in decreasing order by the appeals to novelty, value, gap-filling, importance and usefulness. Note that five of those in Step 1A were subject to double-coding in terms of underlying appeals. For instance, two appeal types, value and importance, were assigned to the following example: "This study offers important theoretical implications to the literature in..." This double-coding explains why there is a higher frequency of rhetorical appeals $(\mathrm{N}=319)$ compared to that of Step $1 \mathrm{~A}(\mathrm{~N}=314)$.

In addition, there are differences in the frequencies of these appeals across the four top journals. Table 4 displays the raw counts and percentages of the occurrence of the six types of appeal in each journal. 


$\begin{array}{ccccccccc} & \text { Scope } & \text { Novelty } & \text { Value } & \begin{array}{c}\text { Gap } \\ \text { filling }\end{array} & \text { Importance } & \text { Usefulness } & \text { N.C.* } & \text { Total } \\ \text { AMJ } & 57 & 17 & 21 & 14(11 \%) & 11 & 3 & \mathrm{~N}= & 57 \\ & (46 \%) & (14 \%) & (17 \%) & & (9 \%) & (2 \%) & 123 & (46 \%) \\ \text { ASQ } & 24 & 19 & 16 & 13 & 11 & 2 & \mathrm{~N}=85 & 24 \\ & (28 \%) & (22 \%) & (19 \%) & (15 \%) & (13 \%) & (2 \%) & & (28 \%) \\ \text { JMS } & 32 & 7 & 7 & 8 & 2 & 0 & \mathrm{~N}=56 & 32 \\ & (57 \%) & (13 \%) & (13 \%) & (14 \%) & (4 \%) & & & (57 \%) \\ \text { JOM } & 22 & 12 & 10 & 3 & 5 & 3 & \mathrm{~N}=55 & 22 \\ & (40 \%) & (22 \%) & (18 \%) & (5 \%) & (9 \%) & (5 \%) & & (40 \%)\end{array}$

Table 4. Distribution of rhetorical appeals across journals.

As shown, these appeals register the highest frequency counts in the AMJ, possibly because of the high premium placed by the AMJ on explicit articulation and justification of theoretical contribution, as evidenced in the journal's publication criteria, which state that "all articles published in the Academy of Management Journal must also make strong theoretical contributions. Meaningful new implications or insights for theory must be present in all AMJ articles..." (AMJ website). Moreover, articles in other journals might have featured less overt strategies to allude to theoretical contributions, such as indexing the congruence between their results and those in prior literature without designating them as contributions.

That said, the distributions of the appeals in each journal seemingly reflects the general trends noted in Table 3, with the appeal to scope standing out distinctly as the leading appeal, though slight variations in the ensuing order can be observed. There are perceptibly lower frequencies of the appeal to importance in JMS and that of the appeal to gap-filling in JOM. Given the rather small corpus of the present study and the absence of the substep of highlighting theoretical contributions in two articles of JMS and JOM, it is feasible that investigating a larger corpus would shed more light on this discrepancy. The following subsections will account for each appeal in greater detail.

\subsubsection{The appeal to scope}

In an appeal to scope, the author precisely specifies the ways in which the new findings expand the scope of or add diversity to the disciplinary knowledge through typical linguistic renditions (e.g., add to existing research, extend the literature, shed light on, or move this research forward). Extracts 1 to 5 show some pertinent instances. 
(1) This study also adds to the literature on classification by studying market classification that is an informal taxonomy based on identity...(ASQ, 1)

(2) Second, we complemented and extended the organizational learning literature by our theorizing... (AMJ, 3)

(3) This broadens our understanding of the potential value of complementary assets for... (ASQ, 6)

(4) A first contribution of our study lies in the extension of Dutton and Dukerich's original observation that members' evolving conceptualiz...(JMS, 1)

(5) ...we begin to build more detailed theory about work-family relationships and move the theoretical focus from the individual to the couple a...(JOM, 5)

This appeal type underscores the value of the new research as a form of knowledge extension in a specific domain, seeking to stretch an established research tradition. Management academics show a strong tendency to apply this appeal type, as indicated by its appearance in nearly $80 \%$ of the RAs in the corpus (see Table 3) and its highest frequency of occurrence in each journal (see Table 4). An analogous appeal for promotional purposes is also reported in Lindeberg's (2004) and Wang and Yang's (2015) examinations of Move 1 in RA introductions in the fields of business and applied linguistics respectively, in which the function of the appeal is to connote the significance of the selected topic by demonstrating its prevalence in the extant literature. Given that this appeal registers the highest occurrence rate in the target corpus, the present research in tandem with past studies points to the predominant role of this value in the RA genre, while each study has its distinct criteria for capturing the value of scope.

\subsubsection{The appeal to novelty}

The appeal to novelty denotes the newness or uniqueness of the research by highlighting its originality with regard to a specific aspect of disciplinary knowledge. This appeal is frequently expressed with attitudinal language that overtly proclaims the work's novelty (e.g., first, novel, new, or unique) or flags the study as "different," as seen in the following text segments. 
(6) ...our study is the first to provide specific theoretical and empirical insights on ... (AMJ, 8)

(7) The present study contributes to the IPT literature a new third line of IPT theory and research-specifically, a dimension pertaining to the way people's IPT relates to how other people perceive and respond to them. (JOM, 3)

(8) My research thus offers a novel explanation for Haas and Hanson's (2005) findings and advances broader theory linking teams' knowledge us...(ASQ, 15)

(9) The present study presents a different aspect of emotion in entrepreneurship ...(JMS, 13)

By foregrounding the study's novel contribution to disciplinary knowledge, this appeal directly addresses the academic concern for newness. Interestingly, given the emphasis on theoretical innovation in the management discipline, it appears in only about 50\% of the RAs, a substantially lower rate of occurrence than the appeal to scope. One caveat is in order, however. This finding should not be interpreted as the weak presence in the current corpus of theoretical novelty, since it may not be featured solely through the discursive choices usually associated with this appeal. It may also be negotiated at varying levels of discourse beyond overt linguistic cues, which is beyond the scope of this research to explore.

In addition to elucidating theoretical novelty, this appeal has also been utilized for other rhetorical purposes, such as spotlighting novelty of research topic, as noted in prior literature investigating the "claiming centrality" Step in Move 1 in business studies (Lindeberg, 2004) and in applied linguistics (Wang \& Yang, 2015), or signaling general research value in the "stating the value" Step in Move 3 of RA introductions in health sciences and humanities/social sciences (Martín \& León Pérez, 2014). This appeal has also been characterized in RAs across various hard and soft sciences as having major academic value for diverse rhetorical purposes (Giannoni, 2010).

\subsubsection{The appeal to value}

This appeal fleshes out a general approach to claiming theoretical contribution, often enacted through such terms as "contribution" or 
"implication", as exemplified below. Given its general nature, some of the discursive choices do not mark the theoretical aspect of the contribution at the clause level, as shown in examples [10] and [13]. They are classified as this rhetorical appeal based upon co-texts, that is, texts prior to or following this appeal.

(10) The results of this study make two contributions. First, they help to validate and stream-line theories of ... (JMS, 9)

(11) Our findings contribute to the leadership, creativity, and attribution literatures in four primary ways. (AMJ, 10)

(12) The theoretical implication is that the information exchange perspective should be extended by explicitly including the motivational dime...(JOM, 10)

(13) ... a primary contribution of our study is to develop theory regarding why this form of impression management is likely to be more persuasive...(ASQ, 14)

As one of the frequently occurring appeal types, "appeal to value" generally acts as an organizing element, often by being placed at the beginning of Move 2, as displayed in the examples [10] and [11]. It foregrounds the overall strength of the novel research, so that readers can gain a broad overview of its potential value prior to the unfolding of each specific theoretical contribution. This appeal may have a powerful impact on readers' perceptions of the value of the related findings. By asserting overall theoretical advancement, this appeal sets readers up to adopt a positive attitude toward the new research.

\subsubsection{The appeal to gap filling}

This substep is adapted from Wang and Yang's (2015) “appeal to problematicity" which refers to a claim of topic centrality by presenting "the conflicts, problems, difficulties, or challenges" that a proposed research topic addresses (168) to refer to claims that the new research is filling a gap in the literature. In the present study, a research gap can be linguistically formulated in various ways, either as a lack of research on the target topic, a previous study's call for more research in a particular domain, or conflicting findings documented in the literature, all of which index that the extant scholarship is insufficient or incomplete to portray or explain a specific phenomenon. A 
theoretical contribution can thus be established by illuminating one aspect of the disciplinary knowledge gap. This appeal can be conveyed through a wide array of linguistic devices such as addressing a specific research gap, meeting the call advanced in former literature, or reconciling conflicting findings noted in previous research, as illustrated in the following extracts.

(14) We begin to fill this gap in the literature by revealing how high levels of flattery and opinion conformity increase CEOs' overconfidence...(ASQ, 2)

(15) ..., this study addresses the lack of multi-level approaches in entrepreneurship... (JMS, 12)

(16) On a related note, this study responds to Schulz's (2001) call for research that can help explain not only how managers recognize and construe the relevance of knowledge (as a precursor to knowledge acquisition), but also how existing understandings of relevance influence organizational capabilities. By explicating the linkages between conceptions of the significance and sources of useful knowledge and subsequent acquisition and use processes, this study achieves the key outcome that the ways in which managers perceive and understand knowledge... (AMJ, 5)

(17) This is a first step to meet the call for more positive organizational studies (Luthans et al., 2008; Luthans \& Youssef, 2007; Youseff \& Luthans, 2007) as our results provide support for the theoretical notion that positive experiences by one individual in the workplace can cross over and influence another, at least in the supervisor-subordinate case (Westman, 2001). (JOM, 1)

(18) Finally, our theoretical extensions and empirical analyses reconcile an important contradiction in the literature regarding the long-term...(AMJ, 8)

As shown above, by appealing to the gap-filling principle, a study can effectively claim a potential theoretical contribution to the field in the sense that a neglected area in the disciplinary knowledge has now been examined, or an academic debate may now be settled. This rhetorical feature has also been identified as one means of underscoring the general contribution of 
the novel research, as reported in Liu and Lim's (2014) study of economics RAs, and in Martín and León Pérez's (2014) research on RA introductions in health and humanities/social sciences.

\subsubsection{The appeal to importance}

This appeal is narrowly defined as the use of evaluative adjectives (e.g., important, significant) to overtly foreground an aspect of the novel research as having important implications for the development of disciplinary knowledge, as displayed in the following extracts [19] and [20]. It may also be enacted through ascribing significant value to a specific finding (see examples [21] \& [22]) that makes its theoretical inroads into disciplinary knowledge, thus underscoring the study's original contribution to the established literature with or without making a bald claim of theoretical contribution.

(19) This study introduces a new and important theoretical perspective to the management literature: the role of firm level desperation. (ASQ, 12)

(20) In light of theory suggesting that top-down and bottom-up approaches be integrated for optimal change effectiveness (Conger, 2000; Dunphy, 2000), our study contributes an important insight with regard to an asymmetrical effect in transitioning between top-down and bottom-up organizing styles. (AMJ, 7)

(21) ...we believe that the unpacking of 'conditions of individual action' into specific and meaningful components is a small but important contribution to current research...(JMS, 10).

(22) Finally, an important finding from this study concerns the explication of and support for pioneering orientation as a distinctly different construct from entrepreneurial orientation. Prior to this study, entrepreneurial orientation was commonly viewed as subsuming market pioneering behaviors ...Thus, pioneering behaviors appear to have significant effects upon firm performance above and beyond those explained by a firm's entrepreneurial orientation. (JOM, 9)

Intriguingly, the appeal to importance has a much lower rate of incidence in claiming theoretical contribution, although it is recognized as a primary 
evaluation criterion of academic discourse (Hunston, 1993; Thetela, 1997; Swales \& Burke, 2003; Giannoni, 2010; Corley \& Gioia, 2011), as shown in Table 1. One major reason to account for its lower incidence here is that, in the prior literature, it is broadly conceived to encompass an extensive array of meanings as an academic value that may be applied to any aspect of a study, whereas the present study has attempted to refine this all-embracing evaluation criterion by confining its meaning to references to theoretical importance or significance, so other usages of evaluative terms are not taken into account.

\subsubsection{The appeal to usefulness}

This appeal associates the research's current contribution with its capacity to evaluate the validity, applicability or explicatory power of existing theory, as the instances [23] and [24] show.

(23) Hence, our research testifies to the promise of extending creativity theory by... (AMJ, 10)

(24) Moreover, we indicate the applicability of the social dilemma literature to the topic of group compensation. (JOM, 2)

The above examples show how the usefulness of a paper's theoretical contribution may be asserted by demonstrating the extension of an existing theory in one domain to other relevant fields. It has the lowest frequency rate among the six appeal types for promoting research value, which can be attributed to the narrow definition of "appeal to usefulness" adopted in the current study. Following the criteria formulated in Hunston (1993), this appeal is restricted to theoretical advancements without taking account of the research's utility in other aspects. Because evidence of practical utility is an important component in Management RAs (Bartunek \& Rynes, 2010; Corley \& Gioia, 2011), future research can address an expanded sense of utility to include other aspects, which may reveal more frequent deployment of appeals to usefulness to elucidate the research's practical contribution.

\section{Conclusions}

As a critical practice to proclaim and advance the scientific progress of a disciplinary field, the act of theoretical contribution has been under- 
explored in the extant literature. This study probes into this rhetorical practice to uncover the evaluative norms utilized to textually construct and promote theoretical contribution. Drawing upon pertinent evaluation frameworks, this study explores the rhetorical appeals utilized to signify theoretical value in one rhetorical act designated as "Highlighting theoretical contribution to the field". The findings indicate a tentative taxonomy of six rhetorical appeal types deployed by RA authors to articulate the theoretical value of novel research in the knowledge landscape. This study thus provides a more comprehensive treatment of a long-standing theme in management scholarship, and has several theoretical and pedagogical implications for promotion of academic value.

First, this research elucidates the typical rhetorical appeals systematically deployed by authors of academic management studies to overtly inscribe the theoretical contributions of their research in their discussion sections. By investigating the evaluative norms for formulating theoretical contribution, this study refines our understanding of what constitutes theoretical contribution and further clarifies the general research value, termed as "significance" in Thetela (1997) or "originality" in Corley and Gioia (2011). Although the past literature in the management discipline places a heavy weight on articulating theoretical contributions in academic publications, how to craft this articulation remains a mystery. The current findings offer a more nuanced understanding on its rhetorical construction.

Second, some of these appeals have also been found prevalent in other rhetorical moves/stepa, such as highlighting research topic importance in business and applied linguistics RA introductions (e.g., Lindeberg, 2004; Wang \& Yang, 2015), or in underscoring research significance across evaluative entities in many hard/soft sciences (Giannoni, 2010; Basturkmen, 2012). Although comparison between studies proves hard due to their different foci and terminologies, this study demonstrates that some evaluative norms can be activated for a variety of rhetorical purposes, and thus contributes to a broader understanding of the system of promotion of academic fields advocated by Wang and Yang (2015).

Third, the pervasive use of rhetorical appeals characterizes the highly promotional nature of the management discipline, as noted in several studies (Corley and Gioia, 2011; Cornelissen \& Durand, 2014; Lindeberg, 2004). Although overt articulation of research value appears to be rigorously executed in management studies, it is possible that such a promotional 
emphasis is textual evidence indexing the evolution of the genre, as previous research has determined the promotional tendency in academic genres given the fierce competition in scholarly publication (Berkenkotter \& Huckin, 1995; Bhatia, 2004; Swales, 2004; Hyland, 2005, 2015; Wang \& Yang, 2015).

Finally, this study can shed more pedagogical light on how to evaluate a new finding to craft its theoretical value. The rhetorical appeals attested to in the current corpus can be compiled into a repertoire of evaluation parameters at the micro (step) level, and students can be provided with evaluation norms to apply to their findings. This is a key step in the formulation of theoretical contribution, supported by comparing the outcomes of the new research with the theoretical literature motivating the research, in order to anchor its academic value to the target knowledge domain. Such evaluative comparison can be a daunting task, and researchers often overreach their empirical findings to drift into overgeneralization in asserting a theoretical contribution (Geletkanycz \& Tepper, 2012). The pedagogical guidelines drawn from this research can assist novice researchers with a nuanced understanding of promotion tactics and offer cognitive tools to assess their empirical findings, thus easing the burden of claiming and legitimizing the value of their research.

In conclusion, it should be borne in mind that generalizations about the rhetorical appeals utilized to promote theoretical contribution in the field of management should be avoided since variations among their frequencies can be observed among the selected journals and also the current corpus is extracted from RAs of the most influential journals. The present findings may need to be verified against a larger corpus within the same discipline or across disciplines. In addition, though the current study demonstrates the prevailing schemes in negotiating the value of theoretical innovations, it places at center stage the act of theoretical contribution but excludes the values constructed in other moves (e.g., empirical/methodological or practical implications), or other RA sections (e.g., the method section). It would be interesting for future research to examine the uses of academic values in different moves of discussion sections or other RA sections, given that to date few empirical studies have addressed academic promotion from this genre-based perspective, except for Wang and Yang (2015) and Lindeberg (2004) on claiming the centrality step of Move 1, both of which center on RA introductions rather than discussion sections. As an undertheorized line of inquiry, more research is needed to inform theory on promotion of academic contributions to theory, particularly by 
differentiating the inventory of academic values associated with a specific move, which can help to articulate the subtle ways in which such promotion is enacted. Such research would not only offer a more thorough understanding of the promotional tactics adopted but also enable novice academic writers to capture more fully the rhetorical practices and their variations depending on immediate contexts and subsequently facilitate their mastery of these rhetorical strategies.

Article history:

Received 16 September 2019

Received in revised form 17 March 2020

Accepted 10 June 2021

\section{References}

Bartunek, J. M., \& Rynes, S. (2010). The construction and contributions of "implications of practice": What's in them and what might they offer? Academy of Management Learning \& Education, 9, 100-117.

Basturkmen, H. (2009). Comment-ing on results in published research articles and masters dissertations in Language Teaching. Journal of English for Academic Purposes, 8, 241-251.

Basturkmen, H. (2012). A genre-based investigation of discussion sections of research articles in Dentistry and disciplinary variation. Journal of English for Academic Purposes, 11(2), 134-144.

Bednarek, M. (2006). Evaluation in media discourse: Analysis of a newspaper corpus. Continuum.

Berkenkotter, C., \& Huckin, T. N. (1995). Genre knowledge in disciplinary communication: Cognition/culture/power. Lawrence Erlbaum Associates.

Bhatia, V. K. (2004). Worlds of written discourse. Continuum.

Biber, D., \& Finegan, E. (1988). Adverbial stance types in English. Discourse Processes, 11, 1-34.

Colquit, J., \& Zapata-Phelan, G. (2007). Trends in theory building and theory testing: A five-decade study of the Academy of Manage-ment. Journal Academy of Management Journal, 50, 1281-1303.

Corley, K., \& Gioia, D. (2011). Building theory about theory building: What constitutes a theoretical contribution? Academy of Management Review 36,12-32.

Corley, K. G., \& Schinoff, B. S. (2017). Who, me? An inductive study of novice experts in the context of how editors come to understand theoretical contribution. Academy of Management Perspectives, 31(1), 4-27.

Cornelissen, J. P., \& Durand, R. (2014). Moving forward: Developing theoretical contributions in management studies. Journal of Management Studies, 51, 995-1022.

Geletkanycz, M., \& Tepper, B. J. (2012). From the editors. Publishing in AMJ-part 6: Discussing the implications. Academy of Management Journal, 55(2), 256-260.

Giannoni, D. S. (2010). Mapping academic values in the disciplines: A corpus-based approach. Peter Lang.

Hambrick, D. C. (2007). The field of management's devotion to theory: Too much of a good thing? Academy of Management Journal, 50(6), 1346-1352.

Hunston, S. (1993). Evaluation and ideology in scientific writing. In M. Ghadessy (Ed.), Register analysis (pp. 57-73). Pinter Publishers

Hunston, S. (2011). Corpus approaches to evaluation: Phraseology and evaluative language. Routledge.

Hunston, S., \& G. Thompson (Eds). (2000). Evaluation in text: Authorial stance and the construction of discourse. Oxford University Press.

Hyland, K. (2005). Metadiscourse: Exploring interaction in writing. Continuum.

Hyland, K. (2015). Academic publishing: Issues and challenges in the construction of knowledge. Oxford University Press.

ISI Web of Science. (2013). Journal citation reports: Social science edition. Thomson Reuters. 
Kanoksilapatham, B. (2005). Rhetorical structure of biochemistry research articles. English for Specific Purposes, 24, 269-292.

Kwan, B. S. C., Chan, H., \& Lam, C. (2012). Evaluating prior scholarship in literature reviews of research articles: A comparative study of practices in two research paradigms. English for Specific Purposes, 31(3), 188-201.

Le, T. N. P., \& Harrington, M. (2015). Phraseology used to comment on results in the discussion section of applied linguistics quantitative research articles. English for Specific Purposes, 39, 45-61.

Lewin, B. A., Fine, J., \& Young, L. (2001). Expository discourse: A genre-based approach to social science research texts. Continuum.

Lindeberg, A. C. (2004). Promotion and politeness: Conflicting scholarly rhetoric in three disciplines. Åbo Akademi University Press.

Locke, K., \& Golden-Biddle, K. (1997). Constructing opportunities for contribution: Structuring intertextual coherence and 'problematizing' in Organizational Studies. Academy of Management Journal, 40, 1023-1062.

Martin, J. R., \& White, P. R. R. (2005). The language of evaluation: Appraisal in English. Palgrave Macmillan.

Martín, P., \& León Pérez, I. K. (2014). Convincing peers of the value of one's research: A genre analysis of rhetorical promotion in academic texts. English for Specific Purposes, 34, 1-13.

Mur-Dueñas, P. (2014). 'The main contribution of this study is...': An analysis of statements of contribution in English published research articles and L2 manuscripts. Journal of Writing Research, 5, 271-283.

Nwogu, K. N. (1997). The medical research paper: Structure and functions. English for Specific Purposes, 16(2), 119-138.

Peacock, M. (2002). Communicative moves in the discussion section of research articles. System, 30, 479-497.

Rousseau, D. M. (2007). Standing out in the fields of organization science. Journal of Organizational Behavior, 28, 849-857.
Shaw, J. D., Bansal, P., \& Gruber, M. (2017). From the editors. New ways of seeing: Elaboration on a theme. Academy of Management Journal, 60(2), 397-401.

Sutton, R. I., \& Staw, B. M. (1995). ASQ forum: What theory is not. Administrative Science Quarterly, 40, 371-384.

Swales, J. (2004). Research genres: Exploration and applications. Cambridge University Press.

Swales, J., \& Burke, A. (2003). It's really fascinating work: Differences in evaluative adjectives across academic registers. In $\mathrm{P}$. Leistyna, \& C. F. Meyer (Eds.), Corpus analysis, language structure and language use (pp. 1-18). John Benjamins.

Swales, J. M., \& Feak, C. B. (2012). Academic writing for graduate students. University of Michigan Press.

Tessuto, G. (2015). Generic structure and rhetorical moves in English-language empirical law research articles: Sites of interdisciplinary and interdiscursive cross-over. English for Specific Purposes 37, 13-26.

Thetela, P. (1997). Evaluated entities and parameters of value in academic research articles. English for Specific Purposes, 16(2), 101-118.

Thompson, G., \& Hunston, S. (2000). Evaluation: An introduction. In S. Hunston, \& G. Thompson (Eds.), Evaluation in text: Authorial stance and the construction of discourse ( $p p$. 1-27). Oxford University Press.

Wang, W., \& Yang, C. (2015). Claiming centrality as promotion in applied linguistics research article introductions. Journal of English Academic Purposes, 20, 162-175.

Weick, K. E. (1995). What theory is not, theorizing is. Administrative Science Quarterly, 40(3), 385-390.

Whetten, D. A. (1989). What constitutes a theoretical contribution? Academy of Management Review, 14, 490-495.

Yang, R., \& Allison, D. (2003). Research articles in applied linguistics: moving from results to conclusions. English for Specific Purposes, 22(4), 365-385.

Fei-Wen Cheng is Professor in Foreign Languages Department at National Chiayi University, Taiwan where she teaches a variety of courses of advanced academic literacy and English for specific purposes. Her main areas of research include academic discourse, genre analysis, and multimodality. 